\title{
PURITY DETERMINATION OF THE STARTING MATERIALS USED IN THE SYNTHESIS OF PHARMACEUTICAL SUBSTANCES
}

\author{
ALEKSANDRA GROMAN*, ELŻBIETA STOLARCZYK and MARIOLA MUCHA

\begin{abstract}
Pharmaceutical Research Institute, R\&D Analytical Chemistry Department,
\end{abstract} \\ 8 Rydygiera St. 01-793 Warsaw, Poland
}

\begin{abstract}
High requirements for the API quality mean that the quality control of the starting material is crucial in the manufacturing process of drug substances. Three sensitive methods for the purity determination of the following starting materials: ethylene glycol (method I), 3-acetylpyridine (method II) and 4-chloromethyl-5methyl-1,3-dioxol-2-one (method III) used in the syntheses of selected drug substances were developed using GC-FID techniques. All the methods were validated according to the International Conference on Harmonization guidelines. The correlation coefficient values were found to be about 0.99 . The calculated RSD values from the replicate injections in the range of $20-120 \%$ of the nominal concentration ensured the precision of the methods.
\end{abstract}

Keywords: gas chromatography, quality control, method validation, bosentan, imatinib

A pharmaceutical R\&D process requires analyses to measure the quality of the materials used for the active pharmaceutical ingredient (API) manufacturing and for monitoring the reactions over time. This is a very important task because potential impurities coming from the carry-over of the chemical reagents and starting materials employed in the synthesis of drug substances can be toxic. Eliminating all the impurities from pharmaceuticals is essentially impossible for both practical and economic reasons. Therefore, it is necessary to develop analytical methods to control them not only in the API but also in the materials used in the API manufacture (1). The reagents typically used contain carbon, are often volatile and cover a wide range of polarities. Therefore, gas chromatography with flame ionization detection (GC-FID) is often the most appropriate technique to be used. The GC-FID is a separation method of choice because it combines both speed and separation efficiency (2).

Impurities can be classified by type (organic, inorganic, solvent) and origin (starting materials, by-products, reagents, degradation products) (3). A starting material is any raw material, intermediate, or drug substance that is used in the synthesis of an active pharmaceutical ingredient and incorporated as a significant structural fragment into the structure of a drug substance (4). One of the basic parameters of the raw materials quality control is their chemical purity examination. Taking into account the intended use of ethylene glycol, 3-acetylpyridine and 4chloromethyl-5-methyl-1,3-dioxol-2-one as the raw material in the manufacture of various pharmaceutical substances, e.g. Bosentan and Imatinib, three gas chromatographic methods for the determination of their purity were developed. Following optimization, these methods using the FID detection and the area normalization method for calculation were validated. To the best of our knowledge, the results of ethylene glycol, 3-acetylpyridine, and 4-chloromethyl-5-methyl-1,3-dioxol-2-one purity analysis by capillary GC have not been previously reported in the literature.

\section{EXPERIMENTAL}

\section{Chemicals and reagents}

The solvents, tested starting materials and their known impurities were purchased from the commercial suppliers:

- 3-acetylpyridine (3-AP), 2-acetylpyridine (2-AP, $\geq 99.0 \%$ ), 4-acetylpyridine (4-AP, $\geq 96.5 \%$ ) from Aldrich (Germany),

$\bar{*}$ Corresponding author: e-mail: a.groman@ifarm.eu 
- ethylene glycol (two baches - EG1 and EG2), toluene ( $\geq 99.8 \%$ ), methanol ( $\geq 99.9 \%$ ), dichloromethane (DCM, $\geq 99.8 \%$ ) from POCh (Poland),

- 4-chloromethyl-5-methyl-1,3-dioxol-2-one from Shanghai FWD (China).

\section{Equipment}

All experiments were performed on a Shimadzu GC-2010 gas chromatograph equipped with a flame ionization detector, split injector and a Shimadzu AOC-20i autosampler. A DB-WAX column (polyethylene glycol), $60 \mathrm{~m}$ long, $0.32 \mathrm{~mm}$ i.d., $0.5 \mu \mathrm{m}$ film thickness, from Agilent Technologies was used in methods I and II. A DB-5 column (95\% dimethyl-5\% diphenyl polysiloxane), $30 \mathrm{~m}$ long, $0.32 \mathrm{~mm}$ i.d., $1 \mu \mathrm{m}$ film thickness, from Agilent Technologies was used in method III.

\section{Methods description}

In all methods the area normalization method was used for the calculation. The purity of all examined substances $(x)$ in \% was calculated from the following equation:

$$
\mathrm{x}=\frac{A_{S} \cdot 100}{\Sigma A_{i}}
$$

where:

$A_{S}$ - the area of the main peak

$A_{i}$ - the area of each peak in the chromatogram (without the peaks from the diluent)

\section{Method I - Purity determination of ethylene glycol Chromatographic conditions and sample prepara-} tion

The following oven temperature program was used: $60^{\circ} \mathrm{C}$, increased at $5^{\circ} \mathrm{C} / \mathrm{min}$ to $240^{\circ} \mathrm{C}$ and held

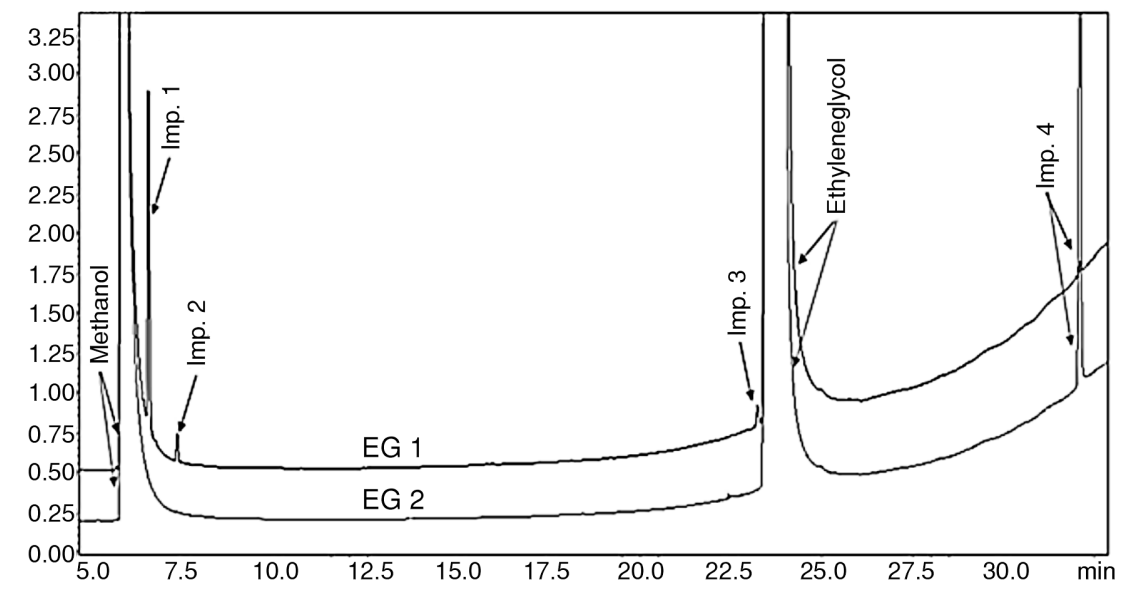

Figure 1. Chromatograms of the sample solutions prepared from EG1 and EG2

Table 1. Validation results of the method I.

\begin{tabular}{|c|c|c|c|c|c|c|c|}
\hline Test & \multicolumn{2}{|c|}{ Acceptance criteria } & Imp. 1 & Imp. 2 & Imp. 3 & Imp. 4 & Main compound \\
\hline \multirow{4}{*}{ Linearity } & \multicolumn{2}{|c|}{$\mathrm{R}^{2} \geq 0.990$} & 0.9985 & 0.9954 & 0.9937 & 0.9991 & 0.9993 \\
\cline { 2 - 7 } & $\mathrm{y}=\mathrm{ax}+\mathrm{b}$ & $\mathrm{a}$ & 698.7 & 49.7 & 46.5 & 1773.6 & 781359 \\
\cline { 2 - 8 } & $\mathrm{b}$ & -780.7 & 347.0 & -19.8 & -3603.3 & 717978 \\
\cline { 2 - 7 } Precision & \multicolumn{2}{|c|}{$\mathrm{RSD} \leq 1 \%\left(\mathrm{t}_{\mathrm{R}}\right)$} & 0.017 & 0.021 & 0.008 & 0.016 & 0.023 \\
\cline { 2 - 7 } & \multicolumn{2}{|c|}{$\begin{array}{c}\text { RSD } \leq 5 \% \text { (Area) } \\
\text { RSD } \leq \text { 5\% for impurities } \\
\text { (Assay\%) }\end{array}$} & 0.96 & 3.39 & 3.92 & 0.45 & 0.59 \\
\hline \multirow{2}{*}{ Range } & $\begin{array}{c}\text { RSD } \leq 1 \% \text { for main compound } \\
\text { RSD } \leq 10 \% \text { for impurities } \\
\text { (Assay\%) }\end{array}$ & 4.12 & 8.06 & 6.00 & 2.99 & 0.006 \\
\hline
\end{tabular}




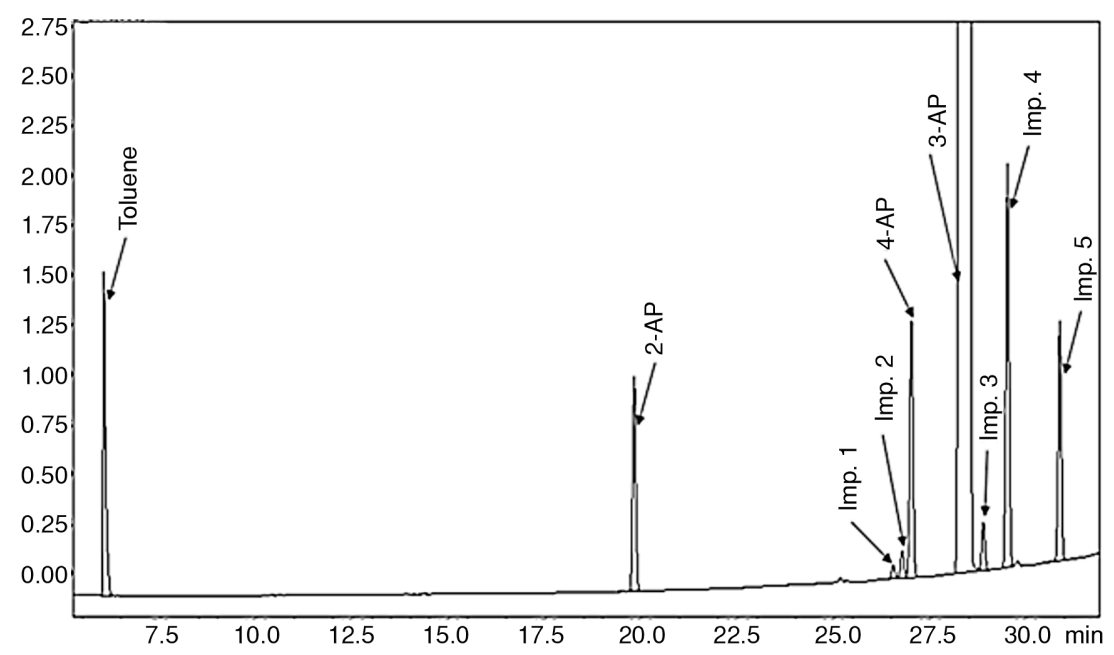

Figure 2. Chromatogram of 3-acetylpyridine spiked with the known impurities at $0.2 \%$

at this temperature for $5 \mathrm{~min}$. The injection port temperature was $240^{\circ} \mathrm{C}$ and the detector temperature was $260^{\circ} \mathrm{C}$. Nitrogen was used as the carrier gas at $100 \mathrm{kPa}$, split $20: 1,0.5 \mu \mathrm{L}$ of the sample solution was injected into the gas chromatograph.

The sample solution was prepared by dissolving $0.5 \mathrm{~mL}$ of the examined ethylene glycol in methanol in a $1.0 \mathrm{~mL}$ volumetric flask.

\section{Method II - Purity determination of 3-acetylpyri- dine \\ Chromatographic conditions and sample prepara- tion}

The following oven temperature program was used: $100^{\circ} \mathrm{C}$ increased at $3^{\circ} \mathrm{C} / \mathrm{min}$ to $240^{\circ} \mathrm{C}$. The injection port temperature was $220^{\circ} \mathrm{C}$ and the detector temperature was $260^{\circ} \mathrm{C}$. Nitrogen was used as the carrier gas at $100 \mathrm{kPa}$, split $100: 1,0.2 \mu \mathrm{L}$ of the examined substance was injected directly into the gas chromatograph.

Method III - Purity determination of 4-chloromethyl-5-methyl-1,3-dioxol-2-one

Chromatographic conditions and sample preparation

The following oven temperature program was used: $60^{\circ} \mathrm{C}$ for $4 \mathrm{~min}$, increased at $5^{\circ} \mathrm{C} / \mathrm{min}$ to $260^{\circ} \mathrm{C}$. The injection port temperature was $220^{\circ} \mathrm{C}$ and the detector temperature was $280^{\circ} \mathrm{C}$. Nitrogen was used as the carrier gas at $60 \mathrm{kPa}$, split $20: 1,0.5$ $\mu \mathrm{L}$ of the sample solution was injected into the gas chromatograph.

The sample solution was prepared by dissolving $100 \mu \mathrm{L}$ of the examined substance in dichloromethane (DCM) in a $1.0 \mathrm{~mL}$ volumetric flask.

\section{RESULTS AND DISCUSSION}

\section{Methods development}

The analyses of the tested compounds were initially carried out using a DB-5 column $(30 \mathrm{~m} \times 0.32$ $\mathrm{mm} \times 1.0 \mu \mathrm{m})$ which seemed to be the most accurate for a wide group of compounds. However, it was not possible to separate the peaks of all impurities from the main peaks of ethylene glycol and 3-acetylpyridine. The impurities peaks were not well separated and the precision of the analyses was not satisfactory. Good results were achieved with a DB-WAX polar column $(60 \mathrm{~m} \times 0.32 \mathrm{~mm} \times 0.5 \mu \mathrm{m})$ for both ethylene glycol and 3-acetylpyridine and with a DB5 non-polar column $(30 \mathrm{~m} \times 0.32 \mathrm{~mm} \times 1.0 \mu \mathrm{m})$ for 4-chloromethyl-5-methyl-1,3-dioxol-2-one. These methods were simple, precise and sensitive for the purity analysis of the tested compounds, and the analysis times were reasonably short.

\section{Methods validation}

The methods were validated by determining the following parameters: specificity, linearity, precision, range in which the normalization method is correct, and the detection limit.

The following acceptance criteria were established:

Specificity: resolution $\left(\mathrm{R}_{\mathrm{s}}\right) \geq 1.5$

Linearity: $R^{2} \geq 0.990, y=a x+b$

Precision: relative standard deviation (RSD) $\leq 1 \%$ (retention time $-\mathrm{t}_{\mathrm{R}}$ ), RSD $\leq 5 \%$ (area), RSD 
$\leq 1 \%$ for the main compound and RSD $\leq 5 \%$ for the impurities (assay\%)

Range of the area normalization method: $80 \%$ $\div 120 \%$ of the nominal concentration in the sample solution or larger RSD $\leq 1 \%$ for the main compound and $\mathrm{RSD} \leq 10 \%$ for the impurities

Detection limit: $\mathrm{S} / \mathrm{N}=3$

\section{Validation of the method I}

Two batches of ethylene glycol were examined: EG1 and EG2. Four impurities (impurity $1 \mathrm{t}_{\mathrm{R}}=$ $6.5 \mathrm{~min}$; impurity $2 \mathrm{t}_{\mathrm{R}}=7.3 \mathrm{~min}$; impurity $3 \mathrm{t}_{\mathrm{R}}=23.2$ min; impurity $4 t_{R}=32.1 \mathrm{~min}$; ethylene glycol $t_{R}=$ $24.0 \mathrm{~min}$ ) were determined in the tested glycols.

\section{Specificity}

The specificity of the method was evaluated by injecting methanol and the sample solutions $(100 \%$ of the nominal concentration). The method was specific for the main compound and its impurities $\left(\mathrm{R}_{\mathrm{s}}\right.$ : methanol/impurity $1-7.5$, impurity 1 /impurity $2-$ 9.0 , impurity $2 /$ impurity $3-170.0$, impurity $3 / \mathrm{EG}-$ 2.4, EG/impurity $4-27.3)$. The chromatograms of the sample solutions prepared from EG1 and EG2 are shown in Figure 1.

\section{Linearity}

The linearity of the method was evaluated by measuring the response of six solutions ranging in concentrations from about $20 \%$ to $120 \%$ of the nominal concentration. The correlation coefficient, yintercept (b), slope of the regression line (a) were calculated and are presented in Table 1.

\section{Precision}

The precision was established by measuring the response of six replicate injections of the sample solution (100\% of the nominal concentration). Relative standard deviations (RSD) were calculated for the retention time $\left(t_{R}\right)$, peak area, assay $(\%)$ and are presented in Table 1.

\section{Range}

The range was established by analyzing 6 solutions in the range $20-120 \%$ of the nominal concentration. The analysis of the solutions has confirmed

Table 2. Validation results of method II for the known impurity.

\begin{tabular}{|c|c|c|c|c|c|c|}
\hline Test & \multicolumn{2}{|c|}{ Acceptance criteria } & Toluene & 2-AP & 4-AP & Main compound \\
\hline \multirow{3}{*}{ Linearity } & \multicolumn{2}{|l|}{$\mathrm{R}^{2} \geq 0.990$} & 0.9997 & 0.9996 & 0.9996 & 0.9994 \\
\hline & \multirow{2}{*}{$y=a x+b$} & $\mathrm{a}$ & 345127 & 302769 & 373409 & 159131242 \\
\hline & & $\mathrm{b}$ & 1519.6 & 349.0 & 311.3 & 767855 \\
\hline \multirow[b]{3}{*}{ Precision } & \multicolumn{2}{|c|}{$\mathrm{RSD} \leq 1 \%\left(\mathrm{t}_{\mathrm{R}}\right)$} & 0.019 & 0.008 & 0.005 & 0.006 \\
\hline & \multicolumn{2}{|c|}{$\mathrm{RSD} \leq 5 \%$ (Area) } & 0.78 & 0.94 & 0.97 & 0.86 \\
\hline & \multicolumn{2}{|c|}{$\begin{array}{c}\mathrm{RSD} \leq 1 \% \text { for main compound } \\
\mathrm{RSD} \leq 5 \% \text { for impurities } \\
(\text { Assay } \%)\end{array}$} & 0.47 & 0.14 & 0.16 & 0.002 \\
\hline Range & \multicolumn{2}{|c|}{$\begin{array}{c}\mathrm{RSD} \leq 1 \% \text { for main compound } \\
\mathrm{RSD} \leq 10 \% \text { for impurities } \\
(\text { Assay } \%)\end{array}$} & 0.50 & 0.69 & 0.79 & 0.014 \\
\hline
\end{tabular}

Table 3. Validation results of method II for the unknown impurity.

\begin{tabular}{|c|c|c|c|c|c|c|c|}
\hline Test & \multicolumn{2}{|c|}{ Acceptance criteria } & Imp. 1 & Imp. 2 & Imp. 3 & Imp. 4 & Imp. 5 \\
\hline \multirow{3}{*}{ Linearity } & \multicolumn{2}{|l|}{$\mathrm{R}^{2} \geq 0.990$} & 0.9993 & 0.9995 & 0.9995 & 0.9994 & 0.9998 \\
\hline & \multirow{2}{*}{$y=a x+b$} & a & 19219 & 38868 & 67660 & 575364 & 329332 \\
\hline & & b & 133.7 & 414.2 & 203.6 & -785.6 & -1013.8 \\
\hline \multirow{3}{*}{ Precision } & \multicolumn{2}{|c|}{$\mathrm{RSD} \leq 1 \%\left(\mathrm{t}_{\mathrm{R}}\right)$} & 0.008 & 0.006 & 0.006 & 0.005 & 0.004 \\
\hline & \multicolumn{2}{|c|}{$\mathrm{RSD} \leq 5 \%$ (Area) } & 1.39 & 1.61 & 0.98 & 1.18 & 0.50 \\
\hline & \multicolumn{2}{|c|}{$\mathrm{RSD} \leq 5 \%$ for impurities (Assay $\%$ ) } & 0.83 & 1.22 & 0.24 & 0.32 & 0.51 \\
\hline Range & \multicolumn{2}{|c|}{ RSD $\leq 10 \%$ for impurities (Assay $\%$ ) } & 1.39 & 1.75 & 1.20 & 1.36 & 1.68 \\
\hline
\end{tabular}




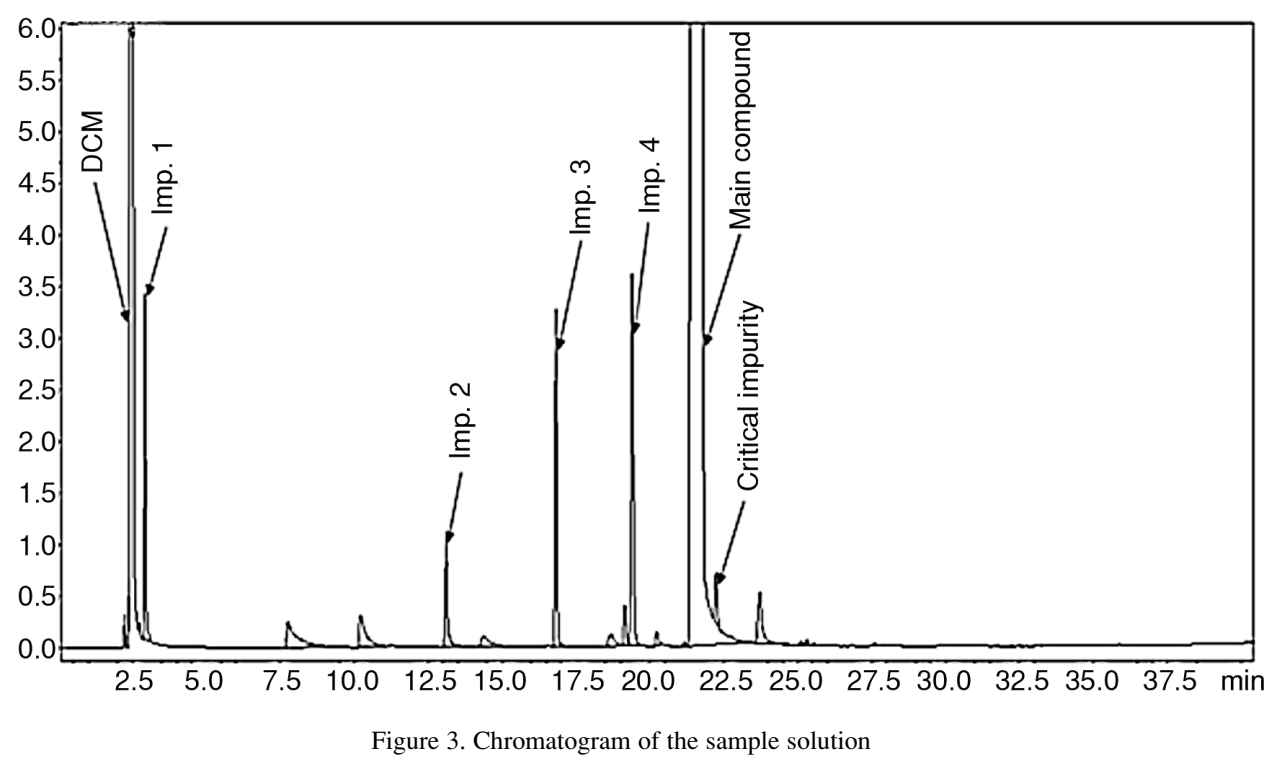

that the purity test results are repeatable and that the method is linear for the main compound and the impurities $1-4$. The range in which the area normalization method is correct: $20 \% \div 120 \%$ of the nominal concentration in the sample solution. The RSDs are presented in Table 1.

\section{Detection limit}

The detection limit (LOD) was calculated as the concentration which generated the peak of ethylene glycol about 3 times as high as the noise's height $(0.0004 \%$ of the nominal concentration in the sample solution).

\section{Validation of the method II}

Besides the main compound (3-acetylpyridine $\mathrm{t}_{\mathrm{R}}=28.5 \mathrm{~min}$ ), three known impurities (toluene $\mathrm{t}_{\mathrm{R}}=$ $6.0 \mathrm{~min} ; 2$-acetylpyridine $t_{R}=19.8 \mathrm{~min} ; 4$ acetylpyridine $t_{R}=27.0 \mathrm{~min}$ ) and five unknown impurities (impurity $1 \mathrm{t}_{\mathrm{R}}=26.5 \mathrm{~min}$; impurity $2 \mathrm{t}_{\mathrm{R}}=$ $26.8 \mathrm{~min}$; impurity $3 \mathrm{t}_{\mathrm{R}}=28.9 \mathrm{~min}$; impurity $4 \mathrm{t}_{\mathrm{R}}=$ $29.5 \mathrm{~min}$; impurity $5 \mathrm{t}_{\mathrm{R}}=30.9 \mathrm{~min}$ ) were determined in the tested substance.

\section{Specificity}

The specificity of the method was evaluated by injecting the sample spiked with the known impurities (toluene, 2-acetylpyridine and 4-acetylpyridine) at $0.2 \%$ (specification limit). The method was specific for the main compound and its impurities $\left(\mathrm{R}_{\mathrm{s}}\right.$ : toluene/2-AP -111.0, 2-AP/impurity $1-44.2$, impurity 1 /impurity $2-1.5$, impurity $2 / 4-\mathrm{AP}-1.5$,
4-AP/3-AP - 7.1, 3-AP/impurity $3-2.0$, impurity 3 impurity $4-4.2$, impurity 4 /impurity $5-9.3$ ). The chromatogram of the sample solution spiked with the known impurities at $0.2 \%$ is shown in Figure 2.

\section{Linearity}

The linearity of the method was evaluated by analyzing the sample spiked with the known impurities at $0.2 \%$ with the use of five different injection volumes $(0.1-0.5 \mu \mathrm{L})$. The correlation coefficient, y-intercept (b), slope of the regression line (a) were calculated and are presented in Tables 2 and 3.

\section{Precision}

The precision was established by measuring the response of six replicate injections of the sample spiked with the known impurities at $0.2 \%$. RSDs were calculated for the retention time, peak area, assay (\%) and are presented in Tables 2 and 3.

\section{Range}

The range was established by analyzing the sample spiked with the known impurities at $0.2 \%$ with the use of five different injection volumes $(0.1$ $-0.5 \mu \mathrm{L})$. The results of RSD for the assay (\%) of the impurities and 3-acetylpyridine are presented in Tables 2 and 3. An analysis using different injection volumes has confirmed that the purity test results are repeatable. The range of the injection volume in which the area normalization method is correct: 0.1 $\div 0.5 \mu \mathrm{L}$ of the injection volume. 


\section{Detection limit}

The solutions of different decreasing concentrations of the known impurities were used for the determination of the detection limit (LOD). The concentration which generated the peak about 3 times as high as the noise's height was established as the LOD (2-acetylpyridine: $12 \mu \mathrm{g} / \mathrm{mL}$; 4-acetylpyridine: $11 \mu \mathrm{g} / \mathrm{mL}$; toluene: $4 \mu \mathrm{g} / \mathrm{mL}$ ).

\section{Validation of the method III}

Apart from the main compound $\left(t_{R}=21.7 \mathrm{~min}\right)$ in the tested substance, many impurities, including four major ones (impurity $1 \mathrm{t}_{\mathrm{R}}=2.9 \mathrm{~min}$; impurity $2 t_{R}=13.1 \mathrm{~min}$; impurity $3 t_{R}=16.8 \mathrm{~min}$; impurity $\left.4 t_{R}=19.4 \mathrm{~min}\right)$, were determined.

\section{Specificity}

The specificity of the method was evaluated by injecting DCM and the sample solution $(100 \%$ of the nominal concentration). The method was specific for the main compound and its main impurities $\left(\mathrm{R}_{\mathrm{s}}\right.$ : $\mathrm{DCM} /$ impurity $1-6.1$, impurity $1 /$ impurity 2 110.5 , impurity 2 /impurity $3-31.8$, impurity $3 /$ impurity $4-21.7$, impurity $4 /$ main compound -9.0 ). The nearest peak $\left(t_{R}=22.2 \mathrm{~min}\right)$ behind the main compound is the impurity critical for the specificity. The resolution for the critical pair of the analytes was 1.8. The chromatogram of the sample solution is shown in Figure 3.

\section{Linearity}

The linearity of the method was evaluated by measuring the response of six solutions ranging in the concentrations from about $20 \%$ to $120 \%$ of the nominal concentration. The correlation coefficient, $y$-intercept (b), slope of the regression line (a) were calculated and are presented in Table 4.

\section{Precision}

The precision was established by measuring the response of six replicate injections of the sample. RSDs were calculated for the retention time, peak area, assay (\%) and are presented in Table 4.

\section{Range}

The range was established by analyzing 6 solutions in the range of $20-120 \%$ of the nominal concentration. The analysis of the solutions has confirmed that the purity test results are repeatable and that the method is linear for the main compound and impurities $1-4$. The range in which the area normalization method is correct: $20 \% \div 120 \%$ of the nominal concentration in the sample solution. The RSDs are presented in Table 4.

\section{Detection limit}

The detection limit (LOD) was calculated as the concentration which generated the peak of 4-chloromethyl-5-methyl-1,3-dioxol-2-one about 3 times as high as the noise's height $(0.0016 \%$ of the nominal concentration in the sample solution).

\section{CONCLUSIONS}

These are the first methods ever reported in the literature for the purity control of ethylene glycol, 3-acetylpyridine and 4-chloromethyl-5-methyl-1,3dioxol-2-one. The GC-FID methods are specific, linear, sensitive and precise. The validation results demonstrate that the analytical procedures are suitable for the intended purpose. Three hereby presented gas chromatographic methods with the area normalization method for the calculation can be used for the standard quality control of the starting materials in the synthesis of various pharmaceutical substances, e.g. Bosentan and Imatinib.

Table 4. Validation results of the method III.

\begin{tabular}{|c|c|c|c|c|c|c|c|}
\hline Test & \multicolumn{2}{|c|}{ Acceptance criteria } & Imp. 1 & Imp. 2 & Imp. 3 & Imp. 4 & Main compound \\
\hline \multirow{3}{*}{ Linearity } & \multicolumn{2}{|l|}{$\mathrm{R}^{2} \geq 0.990$} & 0.9967 & 0.9942 & 0.9960 & 0.9964 & 0.9965 \\
\hline & \multirow{2}{*}{$y=a x+b$} & $\mathrm{a}$ & 978.7 & 667.4 & 1520.4 & 1883.9 & 199364 \\
\hline & & b & -8827.2 & -5056.5 & -7667.8 & -9235.1 & -315799 \\
\hline \multirow[b]{3}{*}{ Precision } & \multicolumn{2}{|c|}{$\mathrm{RSD} \leq 1 \%\left(\mathrm{t}_{\mathrm{R}}\right)$} & 0.064 & 0.039 & 0.019 & 0.014 & 0.015 \\
\hline & \multicolumn{2}{|c|}{$\mathrm{RSD} \leq 5 \%$ (Area) } & 0.83 & 2.24 & 0.74 & 0.85 & 0.70 \\
\hline & \multicolumn{2}{|c|}{$\begin{array}{l}\mathrm{RSD} \leq 1 \% \text { for main compound } \\
\mathrm{RSD} \leq 5 \% \text { for impurities } \\
(\text { Assay } \%)\end{array}$} & 0.98 & 2.42 & 0.30 & 0.36 & 0.04 \\
\hline Range & \multicolumn{2}{|c|}{$\begin{array}{c}\mathrm{RSD} \leq 1 \% \text { for main compound } \\
\mathrm{RSD} \leq 10 \% \text { for impurities } \\
(\text { Assay } \%)\end{array}$} & 9.34 & 7.01 & 3.45 & 3.53 & 0.19 \\
\hline
\end{tabular}




\section{Acknowledgments}

The study was supported by the European Union under the European Regional Development Fund No. UDA-POiG.01.03.01-14-062/09-00 "Innovative technologies of cardio-vascular medicines of special therapeutic and social importance".

\section{REFERENCES}

1. Snodin D.J., McCrossen S.D.: Regul. Toxicol. Pharmacol. 63, 298 (2012).
2. King B., Westwood S.: Fresenius J. Anal. Chem. 370, 194 (2001).

3. Wadekar K.R., Bhalme M., Rao S.S., Reddy K.V., Balasubrahmanyam E.: Evaluating Impurities in Drugs (Part I). Pharm. Tech. 36, 46 (2012).

4. ICH Q7 Good Manufacturing Guide For Active Pharmaceutical Ingredients (2001).

Received: 23.03.2018 